\title{
The Therapeutic Justice as Alternative to Reduce Criminal Majority in Brazil
}

\section{Victorino $\mathbf{P}^{*}$}

Federal Fluminense University, Niterói, Rio de Janeiro, Brazil

*Corresponding Author: Pedro Victorino, Federal Fluminense University, Niterói, Rio de Janeiro, Brazil, Tel: 21 2629-5000; E-mail: pedro_victorinosouza@hotmail.com

Received date: January 09, 2017, Accepted date: September 27, 2017, Published date: October 05, 2017

Copyright: ( 2017 Victorino P. This is an open-access article distributed under the terms of the Creative Commons Attribution License, which permits unrestricted use, distribution, and reproduction in any medium, provided the original author and source are credited.

\begin{abstract}
In Rio de Janeiro, each hour, a child or a teenager is arrested by practicing some kind of offense, with the 8.380 cases, in 2014 , according to the most important newspapers in the country $(41.53 \%$ for drugs trafficking). Increase, in Brazil, the search for a solution to the problem increases, unfortunately, the wrong way of reducing the criminal majority to 16 years old. This false solution is shared by many sectors of society, including the charge of these prisons sector (Security Bureau), which believes that if the teenager is able to vote at age of 16 , would also be fully able to account for all their actions, including infractions. In the opposite direction, the implementation of social measures, preventive, educational and treatment is necessary, able to avoid the first crime, or its recurrence. It is in this context that the project "Therapeutic Justice," which articulates, cooperatively, law enforcement officers with resources from educational and therapeutic area. In the experience of many teenagers in conflict with the law, JT represents the real possibility of building another life narrative, in order to provide concrete way to prevent premature and permanent marginalization, such as that offered by the reduction of the criminal majority.
\end{abstract}

Keywords: Adolescent; Child; Teenagers; Criminals; Psychoactive substances; Therapeutic justice

\section{Introduction}

According to the newspaper O Globo (one of the most important in Brazil), in Rio de Janeiro "At each hour, a child or a teenager is taken to the Public Ministry or the General Department of Socio-Educational Action (New DEGASE) after take some kind of crime in state". According to the newspaper, in 2014, 8.380 young people were arrested, a number that surpasses almost triple of the number recorded in 2010: 2.806. Also notes that currently, about 1.600 accomplish educational measures in closed regime in the correctional system that has capacity to receive 1.517 . The newspaper further states that the new DEGASE survey, $41.53 \%$ of the gathered young people committed the crime of trafficking; $27.92 \%$ practiced robberies and $13.65 \%$ thefts; $5.23 \%$ were spotted armed. The remaining $11.67 \%$ committed other crimes. It is true that this situation only has deteriorated.

The Statute of Child and Adolescent (ECA) provides for actions to protect children and teenagers, guaranteeing rights when they are threatened or violated. The same statute also mentions the society, the State and the parents or guardians, showing us a whole apparatus of actors who should be responsible for such protective measures. SCA (ECA) also establishes educational measures for children who are in conflict with law. Making us remember a great achievement for any proposal set forth with the same statute, but still in the background of the information's of the newspaper "O Globo", remain us the questions: Which have led to the increase of juvenile delinquency? SCA is effective in its determinations or in the social structures, political and family do not guarantee its guidelines?

The reality and the data have shown that today we are indeed faced with a problem, the great increase of criminal acts committed by adolescents. And some relevant issues are gaining proposed by different sectors, increasing the search for solutions that tackle this problem. Lately, the proposal to reduce the criminal majority to 16 years old, have been announced for different social services and researches in Brazil. That has caused a serious discussion. In a research conducted in 2007/2008, in an admission institution for teenagers (in the state of Rio de Janeiro) who committed crimes [1], where the writers sought to look at the profile of these adolescents, there is interesting requirements to be appreciated. The aim of the research was to have an amplitude profile of adolescents serving time measure in the unit, just like to understand the trajectory of life of these teenagers. The total sample of 105 adolescents, according one researcher, is not statistically significant, but it is representative. At that time the institution housed about 130 inmates. As for color, 44 (41.9\%) declared themselves mixed race, 39 (37.1\%) said they were black and $21(20 \%)$ said that they were white.

\section{According to the researcher:}

$80 \%$ declared they were not going to school when they were arrested, and the average time out of school was a year and a half. Another relevant fact is that young people average is in 4th grade, which highlights certain school delay, given the average age of the aforementioned internal. In general, they have an average of six years of school delay, which corresponds to the gap about to the grades in which the student should ideally be in school, according to their age [1]. Remembering that in the interview time, the teenagers were between 15 and 17 years old. Of the total, $31.4 \%$ were 16 years old, $24.8 \%$ were 15 and $20 \% 17$ years old. Considering the use of psychoactive substances, $79 \%$ reported consuming some type frequently. $88 \%$ of these alleged use of cannabis. After comes crack, with $27.7 \%$; cocaine, $24.1 \%$; ecstasy, with $21.7 \%$; the "loló", with $19.3 \%$; and the ether spray, to $15.7 \%$.

In reference still to this research [1], is worth mentioning that $80 \%$ reported had been created with the mother's presence. However, only 
$57.1 \%$ reported living with mother, showing the loss of the maternal bond sometime. Those that are created with the father's presence added $29.5 \%$, those that live with the same, amount to $15.2 \%$. $18.1 \%$ of the internal teenagers said they have kids, which shows the alert about how the question of took the father's place. It is important to remember the warning of the newspaper "O Globo" when quoting that $41.53 \%$ of the gathered young people committed trafficking crime. The model and cultural-historical paradigm, based on Vygotsky and others writers, doesn't consider the man as a machine (engine) or as a single alived organism (organicism), but as a social being done "in and by social relations" [2].

In historical-cultural conception one cannot look at the problem of the violation act of the adolescents without looking and understand the life history and the context that they are inserted. The fact of the difficulty related to education; drug use; breaking with family ties; the inclusion in the drug traffic as a possibility of life and, in some cases, as "the possibility"; skin color; the conception of fatherhood even in adolescence added with some other features also point to proposals regarding public policy. Knowing the breakthrough strategies such as SUS considers the question of promoting as the quality of life, SUAS understands the importance of strengthening ties and the fight against poverty. It is noteworthy that Brazil still lives big problems in the execution of their strategies in play and develop programs that somehow reach and protect the poor, the black and even the teenager (poor and black). It is clear that we face a system of interconnected things, complex and that need a wide comprehension on the context in which it operates.

In the Report of the visits performed simultaneously in 22 Brazilian states and the Federal District in 2006, Federal Council of Psychology and Order of Brazil's Federal Council of Lawyers made Human Rights Inspections, showing in some away pictures of juvenile detention units in conflict with law. In all, 30 units were visited. In $56.66 \%$ the commission of $\mathrm{OAB} / \mathrm{CFP}$ received explicit claims of beatings. $17 \%$ were without any education which hurts Statute of Children and Adolescents beyond the principles of human rights, segregating, marginalizing its internal and not presenting proposals for the preparation of the social inclusion, which is the goal of its existence. $50 \%$ were out of professional programs. $80 \%$ have inadequate housing, poor, unhealthy, adding to the overpopulation that inhabits them. $56.66 \%$ have no legal or public defender, reports of teenagers who rarely talk to their lawyers. Internals complain about the lack of information about their procedural situation.

It is worth mentioning that in all data presented in the report, is included the Institute Padre Severino, Provisional Internament Unit Internment of Rio de Janeiro, replaced in 2012 by Center Dom Bosco according the newspaper "O Dia", in order to humanize and improve the structure and ended to the long history of rebellion and abuse. One of the proposals that pass today in the Brazilian congress in effect and proposal of some politicians is the proposed constitutional amendment (PEC) 171/93 that reduces the criminal majority from 18 to 16 years old. The proposal was shelved since 1993, but now is considered priority for the bench known as the "bullet bench", that consists of parliamentarians linked to the public security forces and has increased a lot in the last election. Increases, in Brazil, search solution to the problem, unfortunately, to the wrong way of reducing the criminal majority to 16 years old. People that defend PEC 171/93, claim that the teenager is able to vote at the age of 16 years old, would also be fully able to account for all their actions, including the infractionals. This false solution is shared by many parts of society, including the charge of these prisons sector (Security Bureau).

\section{Measures the opposite direction:}

Looking briefly for the construction history that we call primary care today in Brazil and care adopted over the years, we see a transformation to get to that we now recognize as basic care. As a framework for world discussion at the conference in Alma-Ata in 1978, where they discussed ways to make health "based in primary care"[3], directly influenced that we now know as concepts go to permeate a health practice. Since then, the idea of health being considered absence of disease began to be deconstructed. Instead of this, health concept assumes for example physical, mental, social well-being and [3] it becomes considered as a fundamental human right. In the new political constitution of the 80 s, society starts breathing the desire for changing in the health system.

As a result of some movements we see the 1988 Constitution crossed by new perspectives on health. Other laws (1990) that came to regulate SUS, still indicate more forward to great turn page in health practices in Brazil, and can still be regarded as a great achievement of health reform movement, for example Law 8,880/1990 presents 13 guiding principles of public health care emphasizing the universality, comprehensiveness, equity and community participation in the system management. As we see since 1990, Brazil has been undergoing transformations around the new model of health, primary care is reorienting the care model and is now considered as a strategy to strengthen the health system, also "constitutes as organizer and integrating core of the health services"[4]. The model adopted for strengthening primary care shares is the Family Health Strategic (ESF).

Family Health Strategy (ESF) can be identified as the transformation of an ideological discourse into political action, forming different links between health and population services. "Promote health involves an individual act or intervene in the context that it is inserted in a space that he lives" [5]. This mechanism provides as a priority the family in the place that it lives, physical and social environment, raising health practices that are beyond curative health ideas. Other requirements make ESF a differentiated practice, because it is the gateway for a regionalized and hierarchical system; performance in certain territories under their responsibility; intervention on the risk factors that are present in the community; encourage the community to exert social control over the health service actions; promote commitments ties and also highlight the performance of education and promotion of health in a comprehensive manner. It is also worth mentioning the provision of continuing care and the development of practices aimed intersectoral action.

In order to strengthen the practices of ESF were created in 2008 Centers of Support for Family Health (NASF). Consisting of a multidisciplinary team working with Family Health teams sharing actions where the basis is the action for empowering teams and not the gateway. The work between NASF and family health teams made operational with some tools, among them the matrix support, the expanded clinic, the individual therapeutic project (PTS), and the health project in the territory (PST). Taking into account that these tools are articulated and permeate a new practice in primary care.

Juvenile children's psychosocial care centers (CAPSI) are operating daily services aimed at children and adolescents with mental disorders. This equipment consists of a multidisciplinary team based on individual, group and family care. Also has workshops services, visits and home care and community activities and joint actions mainly with 
services of social care, education and justice. In the case of children and adolescents demand CAPSIs account the performance regulation of the health care network gateway, organizing the demand that network services. Coordinate practices to this demand, beyond supervise and train ace primary care teams within the territorial work.

\section{Referring to the work offered by CAPSI:}

All care dedicated to children and adolescents are subjected to common ethical principles: that we treat of natural, unique individuals that should not be reduced to their diagnosis; that the treatment aims at the expansion of social ties and the reduction of suffering, and not the relentless adaptation of the child to a predefined standard of 'normality'; the universal host, so, the principle that services should be open to every controversy that comes to them; the implied forward when it follows up until the new treatment site; the child's listening and their families or guardians throughout the follow-up; the care in the geographic territory and emotional of the user [6].

Lima also notes: "No sector alone can account for everything." Making clear the need to weave a working partnership that can count on medical equipment (health centers, family health teams, CAPS, CAPSI, general hospital and others). Just as he also speaks of nonclinical equipment (school, church, club, welfare services and other services). All complete that is defined as a networking, including as already mentioned joint actions mainly with services of social care, education and justice. One can point out enormous difficulties that these services are effective in the play of its shares, being by the desire of managements in political practices or of the difficulty of professional practices in implementing SUS guidelines. The point in presenting these proposals is to understand the great contribution of health promotion as guiding practices. Although new and still being discussed, are measures that go in the opposite direction the proposal to reduce criminal majority, the proposals primary care appear as great achievements, so basic social protection linked to Unified Social Assistance.

Basic social protection concerns a national political strategy of social assistance with the only system of social assistance, formulated and understood through the National Social Welfare Policy in 2004. It is worth noting that even the 1988 Constitution, social assistance practices were confused with charity, philanthropy and welfare practices. After the federal constitution we see the rise of social assistance, "alongside public social policies of health and social security" [6].

With the proposal of National Social Assistance Policy we see the importance of implementing Unified Social Assistance System (SUAS) with one of the cornerstones of operation, the social and familiarly efforts that has an important role in this policy, because the goal is the centrality in the family, ensuring its survival, accommodating their needs and interests in family life and community, in short, social protection, understanding that family is understood as: "Regardless of formats or models that assume mediates the relationship between subject and community"[7]. And so, complementing and prioritizing actions in the territory where they are included.

In this way National Social Assistance Policy defines the objective of basic social protection:

Prevent any unsafe situations through the development and potential acquisitions and the strengthening of family and community bonds. Intended for the population living in a situation of social vulnerability due to poverty, deprivation (lack of income, poor or no access to public services, among others) and, or, weakening of emotional bonds - relational and social belonging (age discrimination, ethnic, gender or disability, among others) [7].

\section{And even define your gateway and strategies:}

Basic social protection services will run directly in Reference Centers of Social Welfare - CRAS and others basic and public centers of social assistance, so indirectly in the entities and social service organizations in the coverage area of the CRAS [7]. CRAS has operations with families and individuals in the community context, it is responsible for the provision of the Comprehensive Care Program for families, has a provider source of protection and socialization of community members, and among others, promote and mediate the relations with family members and relations with other institutions [7].

CRAS is inserted within its territory that provides tracking to users, promoting family and social life. Protection Service and Integral Care to the Family (PAIF) is one of CRAS responsibility work that has continued working characteristic, strengthening protection function of families, working with combat strategies to break ties, promoting access to and enjoyment of rights and contributing to the improvement of quality of life. Also included in its strategies to promote social and material gains to families; promoting access to benefits, income transfer programs and social assistance services. It is also function of CRAS supports on its places of action, families and members in need of care, promoting listening times and changes in collective spaces, so family experiences.

Intersectoral is understood as a very important strategy for practices in public politic: "The health system should work with different sectors and actors, to impact the determinants of health, and thereby contribute to the activities they can carry out their potential to promote equity " [3]. The actions must be complementary, and reach new goals as they perspectives for example: "The resolution of health problems often involves the collaboration of areas that do not belong to the health system, and, in particular, the interaction with the sectors of social welfare, education and justice " [4]. We still see clearly the position of National Social Welfare Policy:

Services, programs, projects and basic social protection benefits should be coordinated with other local public policies in order to ensure the sustainability of actions undertaken and the role of assisted families and individuals in order to overcome the vulnerable conditions and prevent indicating the potential risk situations. It should also be linked to special protection services, ensuring the realization of the necessary referrals [7]. These are different territories and different subjects that must be understood and met in a comprehensive manner, considering the political action framework that aims the objectives in the constitution of SUS and SUAS.

Over the years, Brazil has been undergoing transformations that cross the various sectors. It can be said that some proposals as those previously presented every day, are being looked at and in a practical way. Many are strengthened, reoriented and others still enjoy experiences that deserve change. With all that is visible proposals are present in the search for solutions, both SUS as SUAS represent consistent proposals, you can ensure for example that they go in the opposite direction the idea of reducing the criminal majority. A pretty consistent proposal and total relevance is the proposal of therapeutic justice/Restorative, "RESTORING HOPE PROJECT: treatment program for adolescents in conflict with the law problems related to drug use." 


\section{Restoring hope project:}

Before the challenge of offering a program that not only met the subjectivity of adolescents with related legal issues to drugs, but that somehow promote the protection of the rights thereof, which entered this project [2]. Observed the increase of juvenile homicides of the population between 15 and 24 years old and considering that the municipalities covered by the program are among the municipalities of greater number of homicides of young people in Brazil [2]. This project was consolidated with a partnership by health/justice that included the following institutions: Childhood Stick and youth of Niteroi and Sao Goncalo, Prosecutor for Children and Youth, São Gonçalo's Municipality, Heloisa Marinho's Research Institute and Transdisciplinary Group of Study and Alcoholism Treatment and Other Dependencies (GEAL), Federal Fluminense University. This work is intended to adolescents in conflict with law, their families and communities, using problems, abuse or dependence on psychoactive substances, who have committed illegal acts. Adding therapeutic interventions and social and educational measures, the aim of this project is to promote conditions for the adolescent achieve and maintain abstinence from substances; reconstitute criminal authority and family ties; interpersonal relationships, feelings and academic and professional performance. Apart from the proposal to extend selfesteem, the ability to endure hardship and the feeling of inclusion and citizenship.

Many young people are living with a gun to his head, either by trafficking, drugs, or social and symbolic violence. How restoring their dignity and perspective? How provide opportunities for treatment, education, professional training and employment? How to ensure that the option that they made for the controller to materialize as real? [2]. It is worth mentioning:

The structural conditions of our society that determine the cause of these problems, the social exclusion, are the same that will generate difficulties to offer concrete opportunities of access, with quality, educational and therapeutic services for teens drug users offenders [2].

The drug court, protective treatment measure to replace the process are founded be voluntary and ethics. Requiring informed consent and the adolescent in question and his family consent. Upon reviews of psychiatric teams and judicial technical report is elaborated, it is addressed to the court, which shall recommend or not the teenager's inclusion in the program, with the level of guidance and time to therapeutic care. The proposal is intended to restore the teenager's quality of life [8]. After analysis of prosecutor, judge and technical teams is defined adolescent inclusion in the program (being accepted for himself and his family). The teenager will be included in the program. Your treatment plan will be set in discussions between services and can be inserted at different levels: ambulatory assistance
( $4 \mathrm{~h}$ per week), intensive outpatient ( $12 \mathrm{~h}$ per week) and community center ( 5 hours per day). This schedule can also be performed in partnership with other services: admissions to treatment centers/ therapeutic communities and hospital detoxification [9].

The activities offered are varied: evaluation (psychiatric, psychological, family and social), quality life course/game of Life, operating/informative groups, work activities, clinical monitoring, individual/family therapy, citizenship workshops and expressive creative, cultural activities, recreational, leisure, community school of computer science, popular education, education group, career counseling, complementary educational activities, group of parents or guardians and others. The project also includes judicial supervision performing some procedures as special audience with the judge, interviews with technical teams of judgment, toxicological surveillance, evaluations (made from reports of technical teams of judgment and therapeutic staff), graduation (ending of treatment and process extinction) and program Exclusion (reopening of the case or application of a new socio-educative measure). The program is operationalized over the period of 24 months, noting the specifics of each case and noting the multidisciplinary approach.

\section{References}

1. Neri NE, Campos LA (2015) Crime, youth and punishment - The hospitalization of young people in conflict with the law in the State of Rio de Janeiro: 1-20.

2. Werner J (2010) Affective-cognitive approach in the prevention and treatment of problems related to drug use. In Silva, Gilberto (org): Policy and Practice Drugs.

3. Machado FRDS, Fonseca AF, Borges CF (2014) The Unified Health System and Health Policies in Brazil. Policies and Care in Mental Health: contributions to professional practice, Ed. Fiocruz.

4. Carvalho MCDA (2014) The Unified Health System and Health Policies in Brazil. Policies and Care in Mental Health: contributions to professional practice, Ed. Fiocruz.

5. Souza ACD, Marques D, Silva DS (2012) Contextualizing the Family Health Strategy in Primary Health Care. Family Health Strategy: Challenges and New Possibilities for Basic Health Care, Ed. UFF.

6. Lima RDCC (2012) Public Social Policies and the Centrality of the Family: implications for assistance in the area of alcohol and other drugs. Alcohol and other drugs: dialogues on contemporary malaise, Ed. Fiocruz.

7. MDS (2004) Ministry of Social Development and Fight against Hunger National Secretariat of Social Assistance. National Policy on Social Assistance.

8. Human Rights (2015) A portrait of the hospitalization units of adolescents in conflict with the law: 1-126.

9. Elenilce B (2016) State of Rio registers, every hour, an apprehension of an offending child or adolescent. 